\title{
2 in NW Australia
}

$6 \quad{ }^{1}$ Dept. of Freshwater and Marine Biology, Institute for Biodiversity and Ecosystem

7 Dynamics, University of Amsterdam, 1098 XH Amsterdam, The Netherlands

$8{ }^{2}$ Oceans Graduate School and ARC Centre of Excellence for Coral Reef Studies, The

$9 \quad$ University of Western Australia, Perth WA 6009, Australia.

$10 \quad{ }^{3}$ The UWA Oceans Institute, The University of Western Australia, Indian Ocean Marine

11 Research Centre, Perth WA 6009, Australia.

$12{ }^{4}$ Department of Biology and Chemistry, University of Bremen, 28359 Bremen, Germany.

13 Trace and Environmental DNA (TrEnD) Laboratory, School of Molecular and Life Sciences,

14 Curtin University, Perth WA 6102, Australia.

$15{ }^{6}$ School of Environmental and Life Sciences, University of Newcastle, Callaghan, NSW 2308,

16 Australia. 
$21 \quad \dagger$ Both authors contributed equally.

22

23 Keywords: coral bleaching, recovery capacity, temperature variability, Kimberley

24 region, Acropora aspera, cryptic species

25 
Abstract

Coral reefs are severely threatened by climate change and recurrent mass bleaching events,

28 highlighting the need for a better understanding of the factors driving recovery and resilience both at

29 the community and species level. While temperature variability has been shown to promote coral heat

30 tolerance, it remains poorly understood how this influences coral recovery capacity. Similarly, few

31 studies have investigated how the presence of cryptic species influences bleaching and recovery

32 responses. Using an integrated ecological, physiological and genomic approach, we examined the

33 recovery of both coral communities and their dominant species from the 2016 mass bleaching event

34 in the macrotidal Kimberley region, NW Australia. We show that recovery of coral communities

35 inhabiting adjacent but environmentally contrasting reef habitats differed dramatically following

36 unprecedented bleaching in 2016. Both intertidal (thermally extreme) and subtidal (thermally

37 moderate) habitats experienced extensive bleaching (72-81\%), but subtidal coral communities had a

38 greater percentage of severely bleached corals than the intertidal community (76\% versus $53 \%)$.

39 Similarly, subtidal Acropora aspera corals suffered much greater losses of chlorophyll $a$ than

40 intertidal conspecifics ( $96 \%$ versus $46 \%$ ). The intertidal coral community fully recovered to its pre-

41 bleaching configuration within six months, whereas the adjacent subtidal suffered extensive mortality

$42(68 \%$ loss of live coral cover). Despite the presence of three cryptic genetic lineages in the dominant

43 coral species, the physiological response of $A$. aspera was independent of host cryptic genetic

44 diversity. Furthermore, both intertidal and subtidal A. aspera harbored symbionts in the genus

45 Cladocopium (previously clade C). Our findings highlight the important role of tidally-controlled

46 temperature variability in promoting coral recovery capacity, and we propose that shallow reef

47 environments characterized by strong environmental gradients may generally promote coral

48 resilience to extreme climatic events. Thermally variable reef environments may therefore provide

49 important spatial refugia for coral reefs under rapid climate change. 
Introduction

Tropical coral reefs are biodiversity hotspots that provide income and resources to millions of people worldwide (Moberg and Folke, 1999); however, they are in serious decline globally due to climate change and a wide range of other stressors (Hughes et al., 2017, 2018, 2019). As recurrent mass bleaching events progressively reduce the recovery time available to coral reefs (Hughes et al., 2018), there is an urgent need to better understand the mechanisms and drivers that promote rapid recovery from extreme climatic events (Graham et al., 2011; Gouezo et al., 2019), both on the community and species level.

Reef-building corals often exist over strong environmental gradients and are characterized by wide variation in thermal tolerance (Bay and Palumbi, 2014; Palumbi et al., 2014; Dixon et al., 2015; Kenkel et al., 2015b), although their bleaching thresholds are typically only $1-2^{\circ} \mathrm{C}$ above their local maximum summer temperatures. Thermal tolerance can vary across latitudes and regional scales

63 (Coles et al., 1976; Berkelmans and van Oppen, 2006; Riegl et al., 2011; Howells et al., 2013) but also over much smaller spatial gradients $(<10 \mathrm{~km})$, including thermally distinct habitats within a single reef (Palumbi et al., 2014; Kenkel et al., 2015a; Schoepf et al., 2015b; Barshis et al., 2018). While much attention has recently focused on how these different thermal environments shape the heat tolerance and bleaching resistance of corals (McClanahan et al., 2005; Castillo et al., 2012; Palumbi et al., 2014; Kenkel et al., 2015a; Schoepf et al., 2015b; Louis et al., 2016; Barshis et al., 2018; Safaie et al., 2018), it is poorly understood how high-frequency environmental variability influences coral recovery capacity, particularly at the species level. This is despite the fact that coral community studies have shown that recovery can be highly heterogeneous (Hoogenboom et al., 2017) and habitat-specific (McClanahan and Maina, 2003; Golbuu et al., 2007; Le Nohaïc et al.,

73 2017), for example due to differences in local environmental conditions and community composition.

74 In addition, specific biological traits, such as the type of algal symbionts, often play an important role 75 in influencing bleaching resistance and recovery (Stat and Gates, 2011; Putnam et al., 2012; Grottoli 
et al., 2014b; Silverstein et al., 2015). Finally, unrecognized species diversity can mask differences in

77 functional ecology, including microhabitat distributions and bleaching resistance (Boulay et al.,

78 2014; Rose et al., 2017), and although it is increasingly being recognized that many coral species

79 may in fact consist of several cryptic species (Knowlton, 1993; Souter, 2010; Ladner and Palumbi,

80 2012; Warner et al., 2015), this is rarely considered in studies investigating coral responses to and

81 recovery from bleaching.

82 Thermally variable and extreme reef environments, such as back-reef environments and tide-

83 dominated reefs (Brown et al., 2000; Palumbi et al., 2014; Schoepf et al., 2015b; Camp et al., 2018),

84 have provided important insights into the mechanisms underlying coral heat tolerance. Therefore,

85 these systems also have the potential to advance our understanding of how corals living in such

86 environments recover from heat stress events. Here, we examined the divergent recovery responses

87 of coral communities in adjacent reef habitats following an unprecedented mass bleaching event in

88 the macrotidal Kimberley region in NW Australia in 2016 (Le Nohaïc et al., 2017; Gilmour et al.,

89 2019). Shallow coral reefs in this region are subject to tidally-induced (up to $12 \mathrm{~m}$ tidal range),

90 extreme environmental gradients (e.g. temperature, light and aerial exposure) that fluctuate strongly

91 across multiple temporal and spatial scales (Dandan et al., 2015; Schoepf et al., 2015b). Using an

92 integrated ecological, physiological and genomic approach, we compared the recovery capacity of

93 two reef habitats with distinct environmental conditions at low tide (Fig. 1): (i) an environmentally

94 extreme and thermally variable intertidal pool where corals regularly get exposed to air and have a

95 naturally elevated heat tolerance, and (ii) a thermally moderate subtidal reef with less heat-tolerant

96 corals (Dandan et al., 2015; Schoepf et al., 2015b). We combined reef-wide ecological surveys with

97 physiological and genetic tissue analyses of the dominant coral species, Acropora aspera, to explore

98 drivers of recovery capacity. 


\section{Study site}

Our study site was located at Shell Island (Shenton Bluff), Cygnet Bay, in the macrotidal

103 Kimberley region of NW Australia (Fig. 1a). Shell Island has a tidal range of $\sim 8 \mathrm{~m}$, which creates

104 extreme environmental gradients across small spatial scales resulting in a mosaic of environmentally

105 different habitats depending on tidal exposure (Dandan et al., 2015; Schoepf et al., 2015b). The

106 intertidal environment $\left(16^{\circ} 28^{\prime} 45.8^{\prime \prime} \mathrm{S}, 123^{\circ} 2^{\prime} 41.3^{\prime \prime} \mathrm{E}\right)$ is a small shallow pool (ca. $200 \times 100 \mathrm{~m}$, Fig.

107 1a) that becomes isolated from the surrounding waters of King Sound during low tide (min. depth

$108 \sim 20-30 \mathrm{~cm}$, average depth $\sim 3 \mathrm{~m}$, max. depth $\sim 7 \mathrm{~m}$ ). Although the pool retains at least $20-30 \mathrm{~cm}$ of

109 water during spring low tides, the upper parts of coral colonies growing there regularly get exposed

110 to air for up to several hours. The associated slack water period lasts for up to 4 hours, with corals

111 experiencing a combination of stagnant flow conditions, high light levels (up to $2400 \mu \mathrm{mol} \mathrm{m}^{-2} \mathrm{~s}^{-1}$ )

112 and short-term maximum temperatures of up to $37^{\circ} \mathrm{C}$ (Dandan et al., 2015; Schoepf et al., 2015b). In

113 contrast, the nearby subtidal environment $\left(16^{\circ} 28^{\prime} 46.8^{\prime \prime} \mathrm{S}, 123^{\circ} 2^{\prime} 36.6^{\prime \prime} \mathrm{E}\right.$; within $200-300 \mathrm{~m}$ of the

114 intertidal; min. depth $0 \mathrm{~cm}$, average depth $\sim 4 \mathrm{~m}$, max. depth $\sim 8 \mathrm{~m}$ ) represents a less extreme

115 environment (Fig. 1a) where corals experience maximum light levels of up to $1800 \mu \mathrm{mol} \mathrm{m}^{-2} \mathrm{~s}^{-1}$ and

116 more moderate temperatures, although average temperatures in the subtidal are the same as in the

117 intertidal. Corals in the subtidal environment are typically not exposed to air during low tides, except

118 during the most extreme spring low tides (i.e., only a few days per year). Short-term maximum

119 temperatures (Fig. 1) as well as daily temperature variability differ strongly between intertidal and

120 subtidal, with intertidal corals being exposed to up to $7^{\circ} \mathrm{C}$ daily temperature variability, whereas

121 subtidal corals only experience up to $3^{\circ} \mathrm{C}$ daily variability (Schoepf et al., 2015b). Both intertidal and

122 subtidal environments feature diverse coral communities dominated by branching Acropora spp. (Le 
123 Nohaïc et al., 2017); however, intertidal corals have a higher heat tolerance than subtidal corals

124 (Schoepf et al., 2015b; Le Nohaïc et al., 2017).

\section{Reef-wide coral health surveys and environmental monitoring}

In the austral summer of 2016, a marine heatwave associated with strong El Niño conditions

127 caused unprecedented mass bleaching in NW Australia, including the Kimberley region (Le Nohaïc

128 et al., 2017; Gilmour et al., 2019; but see Richards et al., 2019). To quantify coral recovery and

129 mortality following this bleaching event, reef-wide coral health surveys were conducted at Shell

130 Island six months after peak bleaching from 18-21 October 2016 using the same methods that were

131 used by Le Nohaïc et al. (2017) to assess coral health prior to and during peak bleaching (13-17

132 January and 6-9 April 2016, respectively). Surveys were conducted along six randomly positioned,

$13315 \mathrm{~m}$ transects in each of the intertidal and subtidal environments. High-resolution photos of a $50 \times 50$

$134 \mathrm{~cm}$ quadrat were taken every $0.5-1 \mathrm{~m}$ along the transect line. Photo-quadrats were analyzed using the

135 software (Trygonis and Sini, 2012). Hard corals were scored using the following four health

136 categories as a categorical bleaching score (McClanahan et al., 2004): unbleached/healthy (H),

137 moderately bleached (M: $<50 \%$ of the colony bleached or colony pale), severely bleached (S: $>50 \%$

138 bleached), and dead (D).

139 From September 2015 until October 2016, water temperature, water level and

140 photosynthetically active irradiance were recorded in both intertidal and subtidal environments.

141 Water temperature was recorded every 15 minutes by HOBO U22 v2 temperature $\operatorname{loggers}\left( \pm 0.2^{\circ} \mathrm{C}\right)$ in

142 both intertidal and subtidal environments. To assess cumulative heat stress, we calculated the days

143 when daily average temperature exceeded the local maximum monthly mean (MMM) temperature

144 over the previous 12 weeks from 1 September 2015 until 18 October 2016 and then accumulated the

145 positive temperature anomalies from these days. This value was then divided by 7 to calculate the

146 metric "w>MMM", which can easily be compared to NOAA's degree heating week (DHW) product, 
147 except that our metric calculates the sum of all positive temperature anomalies exceeding the local

148 MMM, whereas DHW only represents the sum of the positive temperature anomalies exceeding the

149 local MMM by more than $1^{\circ} \mathrm{C}$. This new metric "w>MMM" was developed because it provides more

150 realistic estimates of heat stress at our study site than NOAA's DHW methodology (Le Nohaïc et al.,

151 2017); however, in contrast to Le Nohaïc et al. (2017) we here chose to rename the metric to avoid

152 confusion with the widely used DHW terminology. Bleaching thresholds for both intertidal and

153 subtidal corals were previously experimentally established to be $\sim 32^{\circ} \mathrm{C}$ (Schoepf et al., $2015 \mathrm{~b}$ ), $\sim 1^{\circ} \mathrm{C}$

154 above the local MMM of $30.827^{\circ} \mathrm{C}$ from NOAA's 5-km virtual station North Western Australia

155 (version 2).

156 Water level was monitored continuously over the same time period at both sites using HOBO

157 U20-001-02-Ti water level loggers ( $\pm 0.05 \%)$ and RBR virtuoso water level loggers $( \pm 0.05 \%)$.

158 Downwelling planar photosynthetically active irradiance (PAR) was measured at each site for a few

159 days over a spring tide at three time periods in 2016 (12-17 January, 6-8 and 10-12 April, 17-20

160 October) using Odyssey light loggers. No light data are available from January 2016 due to the

161 logger malfunctioning. Each of the Odyssey loggers was calibrated under water against a factory-

162 calibrated LiCor PAR sensor. All loggers were deployed on tripods approximately $20 \mathrm{~cm}$ above the

163 benthos.

\section{Physiological analyses}

165 In addition to the community surveys, we also tagged 5-10 visibly healthy and pale/bleached

166 colonies of the dominant coral species at our study site, A. aspera, which is widespread on shallow

167 reef habitats in both the Kimberley (Richards et al., 2015) and Indo-Pacific. Corals were tagged in

168 both intertidal and subtidal environments during peak bleaching (April 2016) using cattle tags

169 epoxied to the coral (Z-Spar). The health status of all tagged colonies was assessed in April 2016 and

170 after 7 months of recovery in November 2016 using the Coral Watch ${ }^{\circledR}$ Coral Health Chart where a 
171 change of two units in brightness indicates a significant change in symbiont density and chlorophyll $a$

172 content (Siebeck et al., 2006). Colonies were considered either "healthy" (brightness scale 3.6-6) or

173 "bleached" (brightness 1-3.5). Four branch tips $(\sim 3 \mathrm{~cm})$ were collected from the upper part of all

174 tagged colonies in April and November 2016 for physiological and genetic analyses (see below).

175 However, by November 2016, several of the (mostly bleached) tagged colonies had died or could not

176 be relocated, which led to reduced sample sizes for this time point (Table S1). Corals were collected

177 using exemption \#2549 from the Western Australia Department of Fisheries.

178 Corals were stored at $-80^{\circ} \mathrm{C}$ prior to processing. To quantify bleaching, chlorophyll $a$

179 concentration was determined spectrophotometrically (Jeffrey and Humphrey, 1975) and used as a

180 proxy for bleaching susceptibility. Tissue was removed from the first branch tip using an airbrush

181 and separated into animal and symbiont fraction via centrifugation (2x $10 \mathrm{~min}$ at $3000 \mathrm{~g})$.

182 Chlorophyll $a$ from the symbiont fraction was extracted in $100 \%$ acetone in the dark at $4^{\circ} \mathrm{C}$ for 24

183 hours and the concentration determined spectrophotometrically (Jeffrey and Humphrey, 1975) and

184 then standardized to surface area. Surface area was calculated using the relationship between skeletal 185 mass ( $\mathrm{x}$, in $\mathrm{g})$ and the respective computer tomography (CT)-determined surface area $\left(\mathrm{y}\right.$, in $\left.\mathrm{cm}^{2}\right) \mathrm{of}^{-}$

186 A. aspera skeletons from our study site $\left(\mathrm{y}=9.4871 \cdot \mathrm{x}^{0.7729}, \mathrm{n}=6, \mathrm{R}^{2}=0.99\right)$.

\section{Genetic analyses}

To determine if the presence of morphologically cryptic genetic lineages within our dataset

189 influenced bleaching and recovery responses across the two reef habitats, we used an ultra-low-

190 coverage whole genome sequencing approach to generate genotype matrices. We generated Illumina

191 compatible shotgun libraries using Nextera DNA Library Prep Kits as in Therkildsen and Palumbi

192 (Therkildsen and Palumbi, 2017), which offers a cost effective approach to generating whole genome

193 libraries. Thirty-two individuals (16 from each environment) were individually barcoded and 
194 sequenced on a NextSeq Illumina platform using a 300-cycle kit. We used BOWTIE2 to map reads to

195 the $A$. aspera mitochondrial genome (NCBI reference sequence: NC_022827). Mitochondrial

196 sequence reads were filtered for variant sites with a minor allele frequency greater than 0.05 and with

197 a minimum base and mapping quality of 10. Duplicate reads were removed with SAMTOOLS (Li et

198 al., 2009). We identified variant sites using a genotype likelihood approach in ANGSD (Korneliussen

199 et al., 2014) and used the resulting covariance matrix to carry out a principle components analysis

200 (PCA) in R. We also explored clustering of the data using NGSADMIX (Skotte et al., 2013) to

201 identify admixture proportions among samples assigned to predefined clusters, restricting our

202 analyses to loci scored in $>95 \%$ of individuals. Finally, to identify any differences in symbiont

203 communities between environments, we used BLASTn to map merged paired-end reads from the

204 library to the GeoSymbio ITS2 database (Franklin et al., 2012).

205 Statistical analyses

Coral health surveys. Coral health and community composition was analyzed using

207 Permutational Multivariate Analysis of Variance (PERMANOVAs). Prior to multivariate statistical

208 analysis, count data were converted to percent abundance and square root transformed. The four

209 health categories (UB, M, S, D) across all coral genera were statistically tested for differences

210 between environments (intertidal, subtidal) and time points (January, April and October 2016) using

211 two-way PERMANOVAs, the Bray-Curtis similarity index and 9999 permutations. Transects served

212 as replicates. Additional one-way PERMANOVAs were conducted to (1) test the effect of time on

213 coral health across all genera in the intertidal and subtidal, respectively, and (2) to compare intertidal

214 and subtidal at the recovery time point (Oct). Post-hoc pairwise comparisons were calculated, with $p$ -

215 values adjusted using the sequential Bonferroni correction. Principal Component Analysis (PCA) was

216 used to visualize the data. The software PAST was used for the PERMANOVA and PCA analyses

217 (Hammer et al., 2001). 
219 effect of genetic lineage on coral chlorophyll $a$ concentration was assessed using generalized linear mixed model (GLMM) analysis. GLMM analyses were conducted for (1) corals from all three

221 lineages, and (2) corals from the two main lineages only, to see if the small sample size of the third

222 lineage $(n=3)$ affected the robustness of this analyses. As there was no significant effect of genetic

223 lineage on chla concentration in either case (Table S2), further statistical analysis to test for the effect

224 of environment, health and time on chla concentration was conducted for corals pooled from all three

225 lineages (see below). However, chla data for the dominant lineage only are also presented in the

226 Supplementary Material to facilitate comparison (Fig. S2). Prior to GLMM analysis of the

227 chlorophyll $a$ data, the distribution of the residuals was visually assessed and the data were square

228 root transformed to meet assumptions associated with GLMM analysis.

229 GLMM analysis was then also used to test for the effect of health (healthy and bleached as

230 determined in April 2016), environment (intertidal, subtidal) and time (April, November 2016) on

231 chla concentration. Tukey adjusted $p$-values were used for post hoc tests when main effects were

232 significant. When a significant interaction was observed, multiple pair-wise comparisons were

233 conducted using Tukey adjusted $p$-values. Differences between healthy and bleached corals in their

234 respective environments were tested a priori. GLMM analyses were performed using SAS. $P$-values

$235 \leq 0.05$ were considered significant.

$237 \quad$ Results

\section{Recovery responses of intertidal versus subtidal coral communities}

Coral community health surveys conducted before, during and six months after the 2016

240 bleaching event revealed strong differences in survival and recovery across small spatial scales 
241 (hundreds of meters) (Fig. 1, Table 1). The intertidal coral community suffered $72 \%$ bleaching $( \pm 5$

242 SE; moderately and severely bleached corals combined) but mostly recovered within six months with

243 little mortality (9\% $\pm 5 \mathrm{SE})$ (Fig. 2). In stark contrast, the large majority of the bleached subtidal

244 coral community ultimately died (71\% \pm 11 SE) (Fig. 2), although being separated by only 200-300

245 meters and experiencing a similar though slightly higher degree of bleaching $(81 \% \pm 4$ SE versus

$24672 \% \pm 5$ SE for intertidal). Thus, live coral cover in the intertidal was maintained at essentially pre-

247 bleaching levels (6\% proportional decrease in coral cover), whereas in the subtidal it dropped by

$24868 \%$, resulting in a degraded reef dominated by dead Acropora spp. corals that differed significantly

249 from its pre-bleaching state (Fig. 2a, Table 1).

Despite the different recovery responses, intertidal and subtidal coral communities had a

251 similar composition prior to bleaching and experienced similar levels of heat stress exposure. Both

252 reef environments were strongly dominated by healthy Acropora spp. corals prior to bleaching (Fig.

$2532 \mathrm{a}$ ); thus, the bleaching and recovery response of this genus largely determined the overall recovery

254 trajectory within each environment. Similarly, heat stress in both reef environments accumulated

255 along a similar trajectory, reaching 4.5 and $4.3 \mathrm{w}>\mathrm{MMM}$ in the intertidal and subtidal during peak

256 bleaching, respectively (April 2016; Fig. 1b, c). w $>$ MMM values ultimately peaked in early May

2572016 with 5.8 and 6.2 $\mathrm{W}>\mathrm{MMM}$ in the intertidal and subtidal, respectively, and declined in a similar

258 manner in both environments as temperatures seasonally decreased throughout autumn and winter

259 (Fig. 1b, c). However, daily temperature variability was generally much greater in the intertidal

260 compared to the subtidal, with temperatures reaching short-term maxima of up to $38.1^{\circ} \mathrm{C}$ in the

261 intertidal, yet only $33.8^{\circ} \mathrm{C}$ in the subtidal (Fig. 1b, c).

262

Light levels across spring tides were not consistently higher or more variable in the intertidal

263 as this depended on season (Fig. S1), even though average water depth is generally $\sim 1 \mathrm{~m}$ lower in the

264 intertidal compared to the subtidal (IT: $3.07 \mathrm{~m} \pm 1.82 \mathrm{SD}, \max =6.77 \mathrm{~m}$; ST: $4.07 \mathrm{~m} \pm 1.89$, $\max =$

$2657.89 \mathrm{~m}$ ). In April 2016, both intertidal and subtidal corals experienced average daily light intensities 
of $\sim 500 \mu \mathrm{mol} \mathrm{m}^{-2} \mathrm{~s}^{-1}$ (IT: $514 \pm 519, \mathrm{ST}: 541 \pm 571$ ), and maximum light intensities of 1990 and 2115

$267 \mu \mathrm{mol} \mathrm{m} \mathrm{m}^{-2} \mathrm{~s}^{-1}$, respectively (Fig. S1a). In October 2016, intertidal and subtidal corals experienced

268 similar but slightly lower average light intensities of $\sim 400 \mu \mathrm{mol} \mathrm{m}^{-2} \mathrm{~s}^{-1}$ than in April (IT: $442 \pm 426$,

269 ST: $406 \pm 388$ ), and maximum light intensities were also lower with 1573 and $1357 \mu \mathrm{mol} \mathrm{m}^{-2} \mathrm{~s}^{-1}$,

270 respectively (Fig. S1b).

271 Cryptic genetic diversity and symbiont genus of tagged $\boldsymbol{A}$. aspera corals

272 Using a low-coverage whole genome sequencing approach, we mapped 36,717,172 reads

273 from 32 A. aspera colonies (mean 1,112,642 reads per sample) to the $A$. aspera complete

274 mitochondrial genome. Based on 79 variable sites spread across the mitogenome, we identified three

275 distinct genetic lineages in our dataset (Fig. 3a); however, all three lineages co-occurred in intertidal

276 and subtidal environments and were comprised of both bleached and healthy coral colonies (Fig. 3b).

277 Furthermore, the chlorophyll $a$ concentration of the A. aspera complex was not significantly

278 influenced by host genetic lineage (Table S2). We therefore analyzed the effects of environment,

279 health and time on chlorophyll $a$ concentration pooled across all lineages (see below). Mapping raw

280 reads to a list of dominant symbiont genera identified that all $A$. aspera colonies in both habitats were

281 dominated by symbionts from the genus Cladocopium (previously clade C; LaJeunesse et al., 2018).

282 Due to the low coverage and short reads recovered from the shotgun dataset, however, we could not

283 further resolve Cladocopium to ITS2 types.

284 Chlorophyll $a$ concentrations and survival of tagged $A$. aspera corals

285 Tissue samples collected during and seven months after bleaching revealed that the

286 physiological bleaching and recovery response of $A$. aspera was characterized by significant

287 interactive effects of environment, health status and time (Table S3). Although coral community

288 health surveys showed a relatively similar overall extent of bleaching for both reef habitats, 
chlorophyll $a$ analyses revealed that intertidal $A$. aspera bleached less severely than subtidal $A$.

aspera, losing only $46 \%$ of their area-normalized chlorophyll a concentration compared to $96 \%$ in subtidal corals (Fig. 4a). This relatively higher bleaching resistance was also observed in the community-wide surveys as reflected in the lower percentage of severely bleached corals (53\%) in the intertidal coral community compared to the subtidal community (76\%) (Fig. 2b).

bleached colonies surviving in the intertidal, yet only one bleached colony $(20 \%, \mathrm{n}=1)$ surviving in the subtidal, thus strongly mirroring the trends observed in the coral community surveys (Fig. 2).

However, among the surviving colonies, chlorophyll $a$ concentrations of previously bleached corals were no longer significantly lower compared to the healthy coral and had, thus, fully recovered 7 months after peak bleaching in both intertidal and subtidal environments (Fig. 4b).

Discussion

As coral reefs face more frequent mass bleaching events and reduced recovery times (Hughes et al., 2017, 2018), attention has increasingly focused on how different thermal environments shape the bleaching resistance of corals (McClanahan et al., 2005; Castillo et al., 2012; Palumbi et al., 2014; Kenkel et al., 2015a; Schoepf et al., 2015b; Louis et al., 2016; Barshis et al., 2018; Safaie et al., 2018). However, how recovery from heat stress events is influenced by environmental variability has received much less attention, especially on the species level. We show here that strong environmental variability associated with a naturally extreme, macrotidal reef site not only increases coral heat

309 tolerance as has been shown previously (McClanahan and Maina, 2003; Oliver and Palumbi, 2011;

310 Palumbi et al., 2014; Schoepf et al., 2015b; Safaie et al., 2018), but also promoted rapid recovery of

311 coral communities from mass bleaching.

\section{Thermally variable reef habitats promote rapid recovery from mass bleaching}


Bleaching and recovery responses of coral communities in adjacent reef habitats differed

314 strongly across fine-scale but extreme environmental gradients following unprecedented mass

315 bleaching in the macrotidal Kimberley region of NW Australia in 2016. Both intertidal and subtidal

316 reef habitats experienced extensive, severe bleaching during peak heat stress (Le Nohaïc et al., 2017),

317 with $72 \%$ and $81 \%$ of corals bleached, respectively (Fig. 2b). However, the subtidal coral community

318 had a greater percentage of severely bleached corals than the intertidal community (76\% versus

$31953 \%$ ), indicative of lower heat tolerance as observed in previous experimental work (Schoepf et al.,

320 2015b). These differences in community-wide heat tolerance were further corroborated by the

321 physiological analyses of tagged Acropora aspera corals, the dominant coral species at our study site:

322 bleached subtidal corals lost $96 \%$ of their area-normalized chlorophyll $a$ concentration compared to

323 their healthy-looking counterparts, whereas intertidal bleached corals lost only $46 \%$ of their

324 chlorophyll $a$ concentration (Fig. 4).

325 Surveys conducted six months after peak bleaching further revealed dramatic differences in

326 survival and recovery. The intertidal coral community was able to fully recover to its pre-bleaching

327 health configuration within six months and only lost $6 \%$ of live coral cover (Fig. 2, Table 1). In

328 contrast, the subtidal community only 200-300 meters away suffered extensive mortality (71\%), loss

329 of live coral cover (-68\%) and reduced framework complexity driven by death and overgrowth of

330 branching Acropora corals, resulting in a significantly different community configuration compared

331 to pre-bleaching (Fig. 2, Table 1). The markedly distinct recovery responses contradict results from a

332 meta-analysis finding no evidence for reef zone impacting recovery rates (Graham et al., 2011) but

333 are consistent with other studies showing habitat-dependent reef recovery. For example, thermally

334 variable Kenyan reef habitats suffered less mortality and changes in community composition than

335 thermally less variable habitats after the 1998 bleaching event (McClanahan and Maina, 2003).

336 Similarly, sheltered bays in Palau suffered less mortality and recovered better from the 1998 and

3372010 bleaching events than other habitats due to naturally higher temperatures and lower light levels 
338 (Golbuu et al., 2007; van Woesik et al., 2012). Our findings also agree with recent experimental work

339 showing that two genera of intertidal Kimberley corals (Acropora and Dipsastraea) had a higher

340 bleaching resistance and survival rate than their subtidal counterparts (Schoepf et al., 2015b). Given

341 that the two habitats experienced similar heat stress exposure and were both dominated by heat-

342 sensitive Acropora corals (Le Nohaïc et al., 2017), this points to the more extreme environmental

343 conditions, particularly greater daily temperature fluctuations (Oliver and Palumbi, 2011; Schoepf et

344 al., 2015b; Safaie et al., 2018) and/or high light levels (Brown et al., 2000, 2002) in the intertidal,

345 playing a key role in promoting coral heat tolerance (Schoepf et al., 2015b) and recovery capacity

346 (this study). Since our findings are consistent with those from other reefs characterized by

347 environmental variability (McClanahan and Maina, 2003; Golbuu et al., 2007; van Woesik et al.,

348 2012), we propose that strong, fine-scale environmental gradients may be significant drivers of coral

349 recovery from mass bleaching.

The 2016 bleaching event is the first documented mass bleaching event in the inshore

351 Kimberley region (Le Nohaïc et al., 2017; Gilmour et al., 2019), highlighting that global warming is

352 increasingly also impacting remote coral populations with naturally high stress tolerance (Dandan et

353 al., 2015; Schoepf et al., 2015b), although some areas seem to have escaped bleaching (Richards et

354 al., 2019). This bleaching event coincided with an extremely unusual and dry wet season in the

355 Kimberley (Le Nohaïc et al., 2017), high local night-time temperatures (Richards et al., 2019) and the

356 most extreme tides of the year; thus, it is likely that the presumably increased light and UV stress as

357 well as aerial exposure contributed to the extensive mortality observed in the more heat-sensitive

358 subtidal corals. However, the high survival and rapid recovery of the intertidal community is

359 expected to enhance the longer-term recovery of the subtidal coral community via recruitment, even

360 though we note that bleaching can have negative impacts on coral reproduction (e.g. Szmant and

361 Gassman, 1990). 
362 Limited influence of host cryptic genetic diversity and symbiont genus on recovery responses

Our study showed that the divergent recovery responses of intertidal and subtidal coral

364 communities were not significantly influenced by the presence of cryptic genetic diversity in the host

365 of the dominant coral species, Acropora aspera. We identified three cryptic genetic lineages in our

366 dataset that cannot be distinguished based on morphology; however, neither lineage was associated

367 with a specific habitat nor displayed particular susceptibility/resistance during bleaching. This is in

368 contrast to other cryptic coral species found to have different environmental niches and/or stress

369 tolerance (Boulay et al., 2014; Rose et al., 2017). We caution, however, that two of the three lineages

370 were represented in only a small number of samples. Environmentally extreme habitats may favor

371 cryptic species diversity because evolving under extreme conditions can constrain morphological

372 change, thus resulting in morphological stasis (Bickford et al., 2007). Therefore, our study adds

373 macrotidal reef environments to a growing list of extreme environments, such as underwater karst

374 (Lefebure et al., 2006) or deep-sea environments (Vrijenhoek et al., 1994), which support significant

375 cryptic species diversity.

376 Corals from the Acropora aspera complex from both intertidal and subtidal habitats harbored

377 symbionts from the broadly distributed genus Cladocopium, which is consistent with other work at

378 our study site (Schoepf et al., 2015b) and in the north Kimberley region (Thomas et al., 2014).

379 However, these findings differ from other thermally extreme reef habitats, such as the back-reef

380 pools in American Samoa, where higher proportions of Durusdinium symbionts (LaJeunesse et al.,

381 2018) were found in the pool with higher and more variable temperatures (Palumbi et al., 2014). The

382 genus Cladocopium comprises many physiologically diverse species, which are often locally adapted

383 to a range of environmental conditions (Fisher et al., 2012; LaJeunesse et al., 2018), including high

384 temperatures (Howells et al., 2011). It is therefore possible that intertidal and subtidal corals in our

385 study hosted different species of Cladocopium, and/or that shifts in dominant symbiont genus or 
species occurred during recovery (Grottoli et al., 2014b; Silverstein et al., 2015). However, a growing

387 body of literature suggests that resistance to high temperatures (though not light) can be strongly

388 mediated by the coral host (Baird et al., 2008) and is, thus, often (but not always) independent of the

389 symbiont (Barshis et al., 2010, 2018; Bellantuono et al., 2012; Palumbi et al., 2014). Analysis of

390 finer-scale symbiont dynamics at greater taxonomic and temporal resolution was beyond the scope of

391 this study, but our findings provide a framework for future research investigating this topic.

\section{Conclusion}

In summary, we show here that strong daily temperature fluctuations promoted rapid recovery

of an intertidal coral community from mass bleaching and return to pre-bleaching configurations in a macrotidal, shallow reef system. Our integrated ecological, physiological and genomic approach revealed that the divergent responses of intertidal and subtidal reef habitats to the 2016 bleaching event were largely independent of host cryptic genetic diversity and association with certain symbiont genera. This suggests that the presence of tidally-induced strong environmental gradients at our study site led to local adaptation and/or acclimatization of the coral holobiont to the different environmental conditions in the intertidal and subtidal reef habitat. We caution, however, that we did not resolve symbiont type to species level and two of the three cryptic lineages were only represented

402 in a small number of samples. Furthermore, we were not able to investigate any signals of local 403 adaptation in the nuclear genome since our study focused on the mitogenome. Future research is 404 needed to investigate other traits associated with increased recovery capacity, such as high levels of energy reserves (Grottoli et al., 2014a; Schoepf et al., 2015a) or heterotrophic plasticity (Grottoli et al., 2006; Connolly et al., 2012), as well as the evolutionary and possible genetic mechanisms underlying the higher bleaching resilience of intertidal corals. 
410 mechanisms underlying climate change resilience (e.g. Palumbi et al., 2014). Furthermore, improved

411 recovery from bleaching has also been observed in other reefs with higher or more variable

412 temperatures (McClanahan and Maina, 2003; Golbuu et al., 2007; van Woesik et al., 2012), although

413 temperatures on those reefs are much less extreme than at our study site. Our findings therefore

414 highlight the important role that tidally-controlled temperature variability can play in promoting coral

415 heat tolerance (Schoepf et al., 2015b; Safaie et al., 2018) and we propose that shallow reef

416 environments characterized by strong environmental gradients may generally promote the resilience

417 of local coral populations to extreme climatic events. They may therefore provide critical refugia and

418 spatial resilience to recurrent mass bleaching events, while also providing stocks of stress-resilient

419 coral populations that could be targeted for new management approaches (Morikawa and Palumbi,

420 2019; Schoepf et al., 2019).

421

\section{Conflict of Interest}

423 The authors declare that the research was conducted in the absence of any commercial or

424 financial relationships that could be construed as a potential conflict of interest.

425

426 Author Contributions

$427 \quad$ VS designed the experiments and conducted the field work. MJ analysed the coral health 428 surveys and conducted the physiological analyses. LT and NW conducted the genetic analyses. VS, 429 MJ and LT conducted the statistical analyses. All authors provided feedback and contributed to the 430 final manuscript.

431

\section{$432 \quad$ Funding}


434 of Western Australia (VS, LT and MS; Research Collaboration Award), the ARC Centre of

435 Excellence for Coral Reef Studies (VS and MMc; CE140100020), the Western Australian Marine

436 Science Institution (MMc \&VS), and an ARC Laureate Fellowship awarded to MMc

437 (FL120100049), and ARC Linkage grant (MS, LT and NW; LP160101508).

438

439 Acknowledgments

440 We thank J. Brown, G. Firman, M. Le Nohaïc, X. Chen, D. Thomson, S. Comeau, C.

441 Cornwall and Cygnet Bay Pearl Farm for assistance in the field. Special thanks to the Bardi Jawi

442 people who enabled this research through their advice and consent to access their traditional lands.

443

444 
446 Table 1. Permutational multivariate analyses of variance (PERMANOVA) testing for the effect

447 of environment and time on coral health across all surveyed coral genera. $P$-values $\leq 0.05$ are

448 highlighted in bold.

449

\begin{tabular}{|c|c|c|c|c|c|}
\hline & Factor & $d f$ & $F$-value & $p$-value & $\begin{array}{l}\text { Pairwise } \\
\text { comparisons } \\
\text { (p-value) }\end{array}$ \\
\hline \multirow{3}{*}{$\begin{array}{l}\text { Two-way } \\
\text { PERMANOVA }\end{array}$} & Environment & 1 & 4.35 & 0.0038 & \multirow[b]{3}{*}{ See below } \\
\hline & Time & 2 & 17.45 & 0.0001 & \\
\hline & Interaction & 2 & 3.39 & 0.0009 & \\
\hline \multirow{6}{*}{$\begin{array}{l}\text { One-way } \\
\text { PERMANOVA } \\
\text { Intertidal }\end{array}$} & Time & 2 & 7.27 & 0.0001 & Jan vs April: \\
\hline & & & & & 0.0007 \\
\hline & & & & & Apr vs Oct: \\
\hline & & & & & 0.0020 \\
\hline & & & & & Jan vs Oct: \\
\hline & & & & & 0.2206 \\
\hline \multirow{6}{*}{$\begin{array}{l}\text { One-way } \\
\text { PERMANOVA } \\
\text { Subtidal }\end{array}$} & Time & 2 & 16.13 & 0.0001 & Jan vs April: \\
\hline & & & & & 0.0014 \\
\hline & & & & & Apr vs Oct: \\
\hline & & & & & 0.0020 \\
\hline & & & & & Jan vs Oct: \\
\hline & & & & & 0.0037 \\
\hline \multirow{3}{*}{$\begin{array}{l}\text { PERMANOVA } \\
\text { October }\end{array}$} & Environment & 1 & 8.54 & 0.0024 & $\mathrm{IT} \neq \mathrm{ST}$ \\
\hline & & & & & \\
\hline & & & & & \\
\hline
\end{tabular}



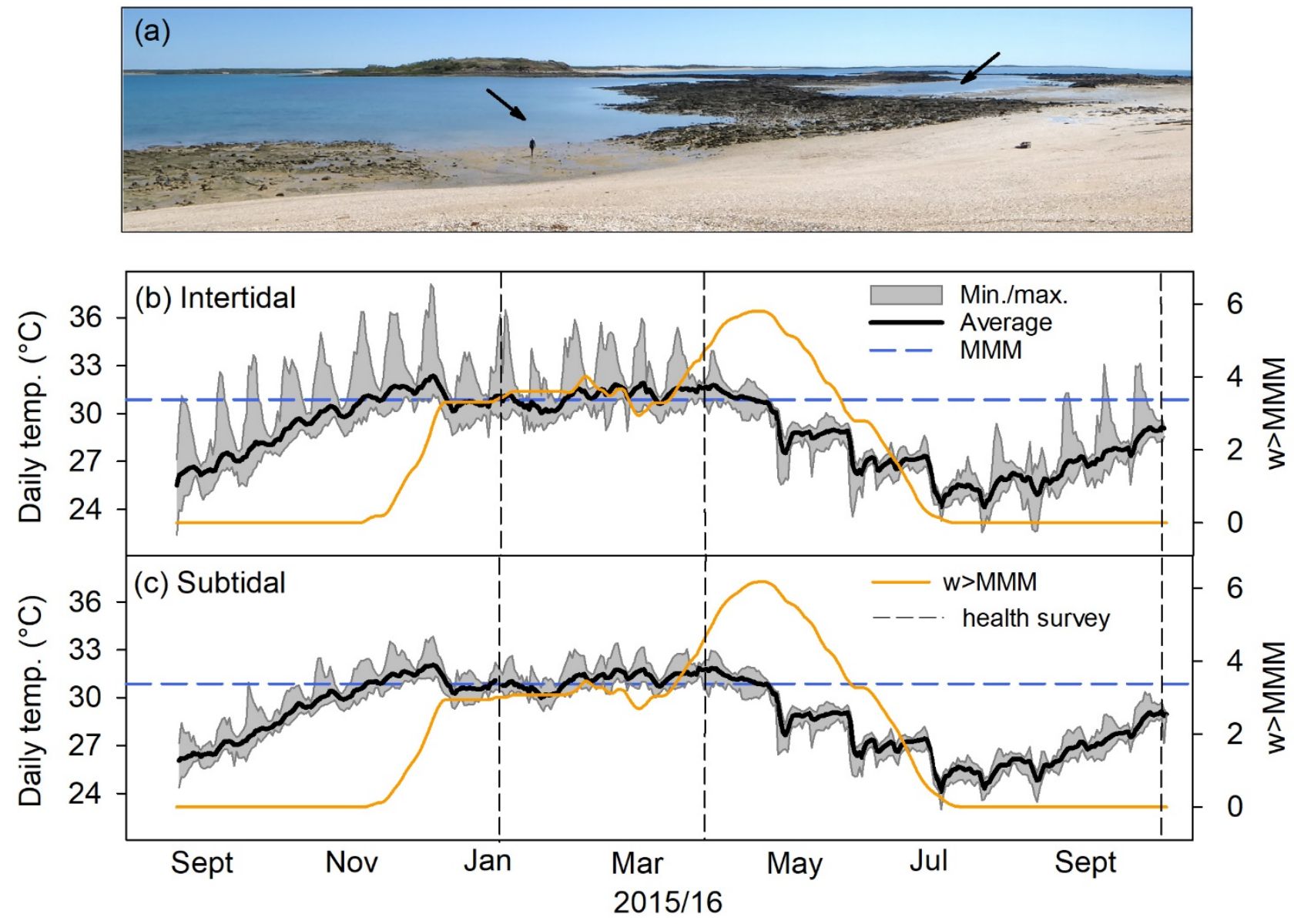

456 The subtidal (arrow centre left) and intertidal (arrow upper right) at Shell Island, Kimberley region at mid- to low tide. (b) Daily average, minimum and maximum temperature in the intertidal from 1

458 September 2015 - 18 October 2016. The blue dashed lines show the local maximum monthly mean

459 (MMM) temperature. Orange solid lines indicate cumulative heat stress above the local MMM

460 (w>MMM; see Methods). Vertical dashed lines indicate when coral health was assessed in reef-wide 461 surveys. (c) Same as in (b) but for the subtidal. 
(a) PCA

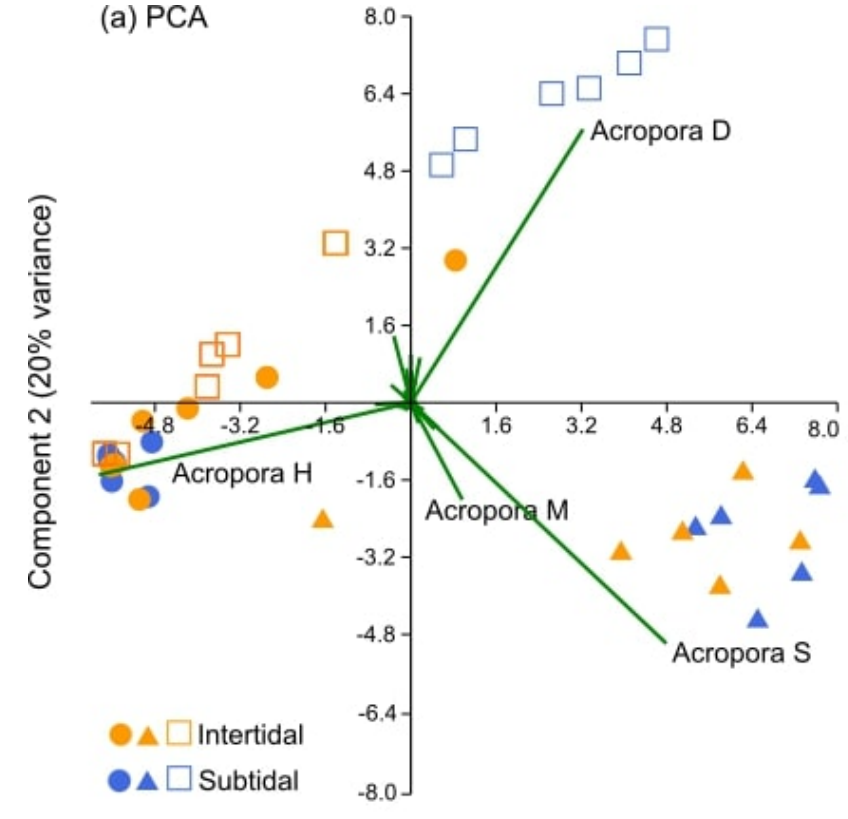

464

465

466

467

468

469

470

471

472

Component 1 (48\% variance) (b) Health categories

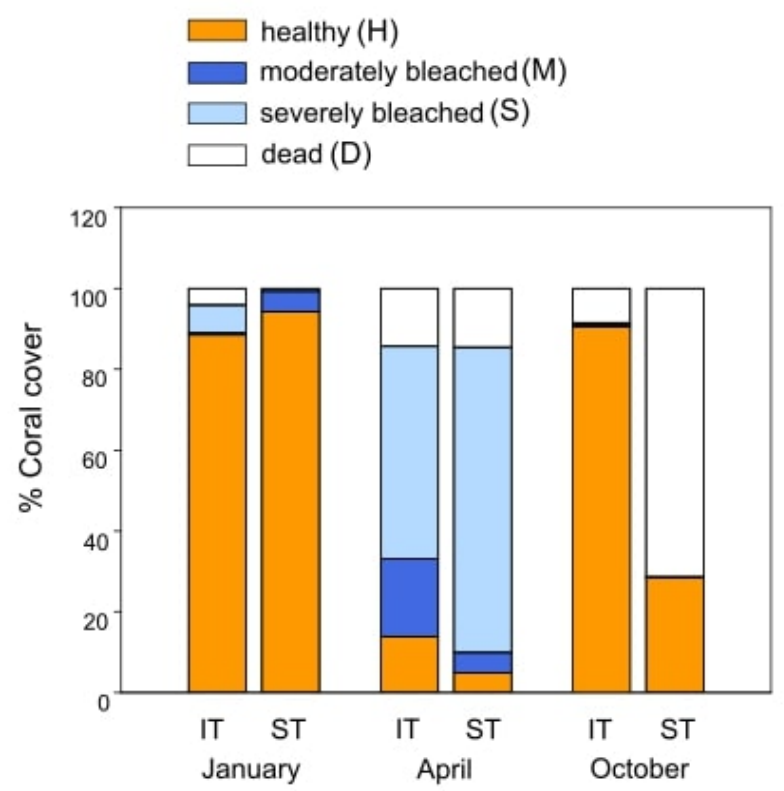

2016

Figure 2. Changes in reef-wide coral health over time based on coral health surveys. (a)

Principal components analysis (PCA) of coral health across all hard coral genera in the intertidal (IT) and subtidal (ST) before (January, •), during (April, $\mathbf{\Delta}$ ) and 6 months after (October, $\square$ ) a bleaching event in 2016. Vectors represent the dominant coral genus Acropora and its associated health status (see below) because it had the greatest influence on overall coral health. (b) Percent coral cover that was healthy $(\mathrm{H})$, moderately bleached $(\mathrm{M})$, severely bleached $(\mathrm{S})$ or dead $(\mathrm{D})$ at the same time points. Data for January and April 2016 are also included in Le Nohaïc et al. (2017). 
(a)

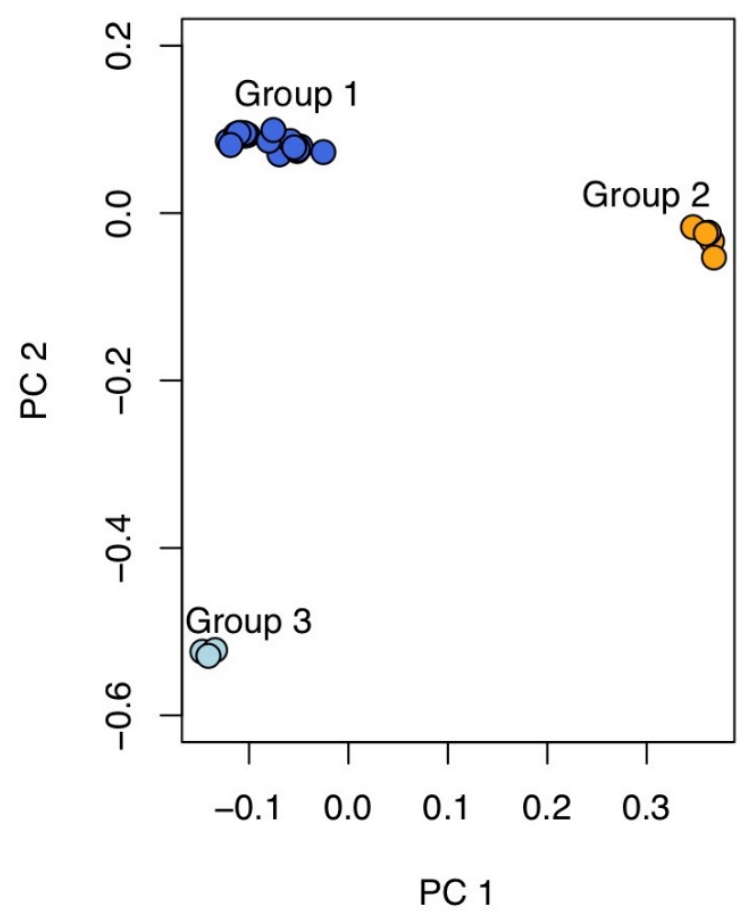

(b)

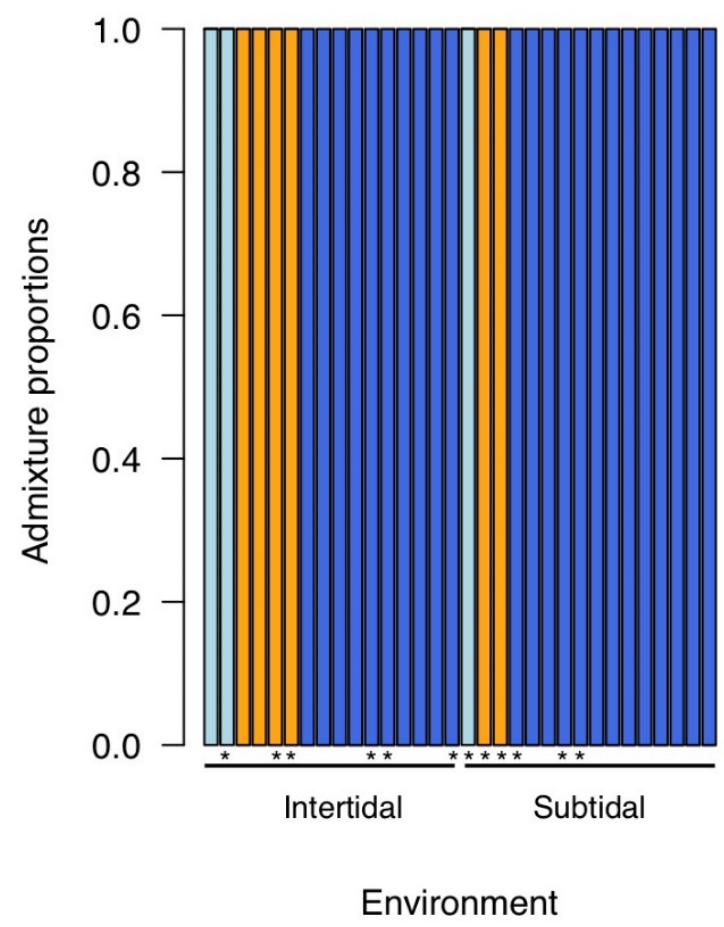

474

475 Figure 3. Cryptic genetic diversity in the Acropora aspera species complex on Shell Island,

476 Kimberley. (a) Principle components analysis and (b) admixture plot showing the presence of three

477 distinct genetic lineages in colonies that were tagged during peak bleaching (April 2016). Asterisks

478 indicate corals that "bleached" (see Methods). 


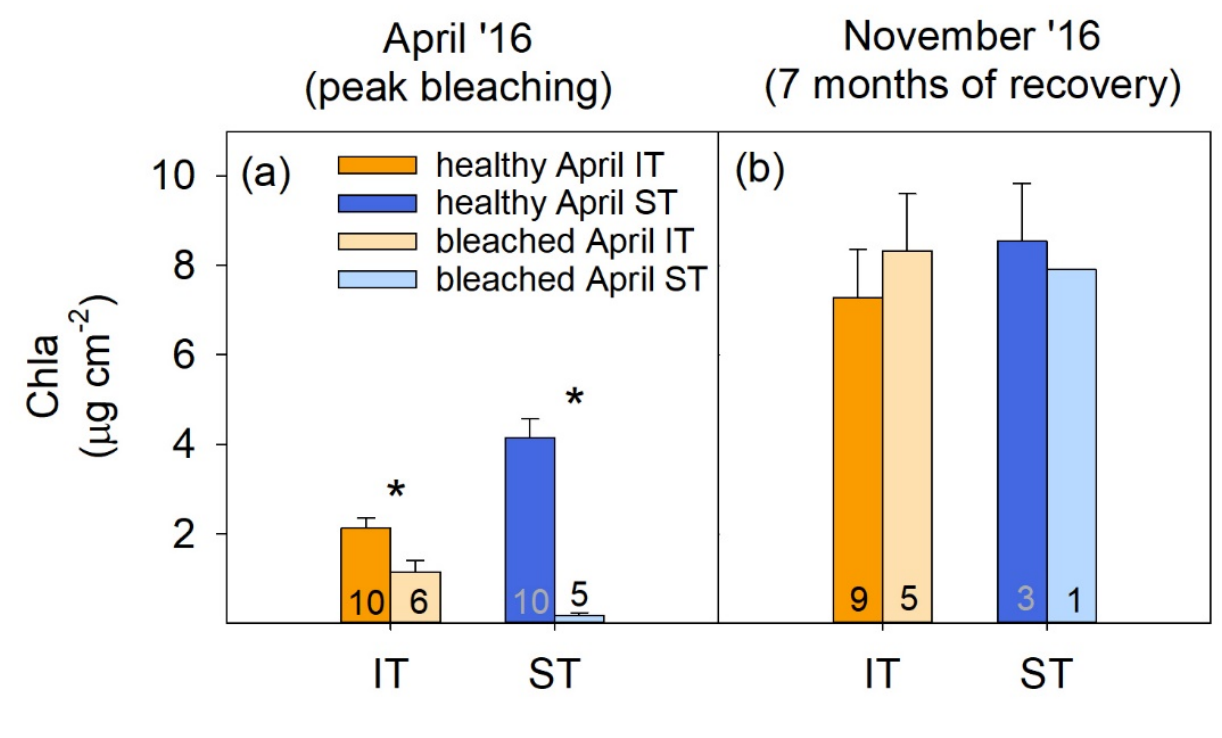

481 Figure 4. Coral physiology. Chlorophyll $a$ concentration of intertidal (IT) and subtidal (ST)

482 Acropora aspera (all genetic lineages) in (a) April and (b) November 2016. Asterisks indicate

483 significant differences between healthy and bleached/recovering corals within a specific environment

484 and time point. Numbers indicate sample size per treatment. Note that only one of the tagged

485 bleached subtidal corals survived.

486 


\section{References}

488 Baird, A. H., Bhagooli, R., Ralph, P. J., and Takahashi, S. (2008). Coral bleaching: the role of the host. Trends Ecol. Evol. 24, 16-20.

Barshis, D. J., Birkeland, C., Toonen, R. J., Gates, R. D., and Stillman, J. H. (2018). High-frequency temperature variability mirrors fixed differences in thermal limits of the massive coral Porites lobata. J. Exp. Biol. 221, jeb188581. doi:10.1242/jeb.188581.

Barshis, D. J., Stillman, J. H., Gates, R. D., Toonen, R. J., Smith, L. W., and Birkeland, C. (2010). Protein expression and genetic structure of the coral Porites lobata in an environmentally extreme Samoan back reef: Does host genotype limit phenotypic plasticity? Mol. Ecol. 19,

Bay, R. A., and Palumbi, S. R. (2014). Multilocus adaptation associated with heat resistance in reefbuilding corals. Curr. Biol. 24, 2952-2956. doi:http://dx.doi.org/10.1016/j.cub.2014.10.044. stress in corals without changes in symbiont composition. Proc. R. Soc. B Biol. Sci. 279, 11001107. doi:10.1098/rspb.2011.1780.

Berkelmans, R., and van Oppen, M. J. H. (2006). The role of zooxanthellae in the thermal tolerance of corals: a "nugget of hope" for coral reefs in an era of climate change. Proc. R. Soc. B Biol. Sci. 273, 2305-2312. doi:10.1098/rspb.2006.3567.

Bickford, D., Lohman, D. J., Sodhi, N. S., Ng, P. K. L., Meier, R., Winker, K., et al. (2007). Cryptic species as a window on diversity and conservation. Trends Ecol. Evol. 22, 148-155.

Boulay, J. N., Hellberg, M. E., Cortés, J., and Baums, I. B. (2014). Unrecognized coral species

510 Brown, B., Downs, C., Dunne, R., and Gibb, S. (2002). Exploring the basis of thermotolerance in the 511 reef coral Goniastrea aspera. Mar. Ecol. Prog. Ser. 242, 119-129. doi:10.3354/meps242119. 
512 Brown, B. E., Dunne, R. P., Goodson, M. S., and Douglas, A. E. (2000). Bleaching patterns in reef

513 corals. Nature 404, 142-143. Available at: http://dx.doi.org/10.1038/35004657.

514 Camp, E. F., Schoepf, V., Mumby, P. J., Hardtke, L. A., Rodolfo-Metalpa, R., Smith, D. J., et al.

515 (2018). The future of coral reefs subject to rapid climate change: Lessons from natural extreme

516 environments. Front. Mar. Sci. 5. doi:10.3389/fmars.2018.00004.

517 Castillo, K. D., Ries, J. B., Weiss, J. M., and Lima, F. P. (2012). Decline of forereef corals in

518 response to recent warming linked to history of thermal exposure. Nat. Clim. Chang. 2, 756-

$519 \quad$ 760. doi:10.1038/nclimate1577.

520 Coles, S. L., Jokiel, P. L., and Lewis, C. R. (1976). Thermal tolerance in tropical versus subtropical

$521 \quad$ Pacific reef corals. Pacific Sci. 30, 159-166.

522 Connolly, S. R., Lopez-Yglesias, M. A., and Anthony, K. R. N. (2012). Food availability promotes

523 rapid recovery from thermal stress in a scleractinian coral. Coral Reefs 31, 951-960.

524 doi:10.1007/s00338-012-0925-9.

525 Dandan, S. S., Falter, J. L., Lowe, R. J., and McCulloch, M. T. (2015). Resilience of coral

526 calcification to extreme temperature variations in the Kimberley region, northwest Australia.

527 Coral Reefs 34, 1151-1163. doi:10.1007/s00338-015-1335-6.

528 Dixon, G. B., Davies, S. W., Aglyamova, G. A., Meyer, E., Bay, L. K., and Matz, M. V (2015).

529 Genomic determinants of coral heat tolerance across latitudes. Science (80-. ). 348, 1460-1462.

$530 \quad$ doi:10.1126/science.1261224.

531 Fisher, P. L., Malme, M. K., and Dove, S. (2012). The effect of temperature stress on coral-

532 Symbiodinium associations containing distinct symbiont types. Coral Reefs 31, 473-485.

533 doi:10.1007/s00338-011-0853-0.

534 Franklin, E. C., Stat, M., Pochon, X., Putnam, H. M., and Gates, R. D. (2012). GeoSymbio: a hybrid, 535 cloud-based web application of global geospatial bioinformatics and ecoinformatics for 536 Symbiodinium-host symbioses. Mol. Ecol. Resour. 12, 369-373. doi:doi:10.1111/j.1755- 
538 Gilmour, J. P., Cook, K. L., Ryan, N. M., Puotinen, M. L., Green, R. H., Shedrawi, G., et al. (2019).

539 The state of Western Australia's coral reefs. Coral Reefs. doi:10.1007/s00338-019-01795-8.

540 Golbuu, Y., Victor, S., Penland, L., Idip, D., Emaurois, C., Okaji, K., et al. (2007). Palau's coral reefs

541 show differential habitat recovery following the 1998-bleaching event. Coral Reefs 26, 319-

$542 \quad 332$. doi:10.1007/s00338-007-0200-7.

543 Gouezo, M., Golbuu, Y., Fabricius, K., Olsudong, D., Mereb, G., Nestor, V., et al. (2019). Drivers of 544 recovery and reassembly of coral reef communities. Proc. R. Soc. B Biol. Sci. 286, 20182908.

$545 \quad$ doi:doi:10.1098/rspb.2018.2908.

546 Graham, N. A. J., Nash, K. L., and Kool, J. T. (2011). Coral reef recovery dynamics in a changing world. Coral Reefs 30, 283-294. doi:10.1007/s00338-010-0717-z.

548 Grottoli, A. G., Rodrigues, L. J., and Palardy, J. E. (2006). Heterotrophic plasticity and resilience in bleached corals. Nature 440, 1186-1189. doi:10.1038/nature04565.

550 Grottoli, A. G., Warner, M. E., Levas, S. J., Aschaffenburg, M. D., Schoepf, V., McGinley, M., et al. (2014a). The cumulative impact of annual coral bleaching can turn some coral species winners into losers. Glob. Chang. Biol. 20, 3823-3833. doi:10.1111/gcb.12658.

Grottoli, A. G., Warner, M., Levas, S. J., Aschaffenburg, M., Schoepf, V., McGinley, M., et al. (2014b). The cumulative impact of annual coral bleaching can turn some coral species winners into losers. Glob. Chang. Biol. 20, 3823-3833. doi:10.1111/gcb.12658. org/2001_1/past/issue1_01. htm. Palaeontologia Electronica, 2001, vol. 41, no 1.

560 al. (2017). Environmental drivers of variation in bleaching severity of Acropora species during an extreme thermal anomaly. Front. Mar. Sci. 4. doi:10.3389/fmars.2017.00376. 
562 Howells, E. J., Berkelmans, R., Oppen, M. J. H. van, Willis, B. L., and Bay, L. K. (2013). Historical

563 thermal regimes define limits to coral acclimatization. Ecology 94, 1078-1088.

564 doi:doi:10.1890/12-1257.1.

565 Howells, J. E., Beltran, V. H., Larsen, N. W., Bay, L. K., Willis, B. L., and van Oppen, M. J. H.

566 (2011). Coral thermal tolerance shaped by local adaptation of photosymbionts. Nat. Clim.

567 Chang. 2, 116-120. doi:doi:10.1038/nclimate1330.

568 Hughes, T. P., Anderson, K. D., Connolly, S. R., Heron, S. F., Kerry, J. T., Lough, J. M., et al.

569 (2018). Spatial and temporal patterns of mass bleaching of corals in the Anthropocene. Science $570 \quad$ (80-. ). 359, 80-83. doi:10.1126/science.aan8048.

571 Hughes, T. P., Kerry, J. T., Álvarez-Noriega, M., Álvarez-Romero, J. G., Anderson, K. D., Baird, A. 572 H., et al. (2017). Global warming and recurrent mass bleaching of corals. Nature 543, 373-377. 573 doi:10.1038/nature21707.

574 Hughes, T. P., Kerry, J. T., Baird, A. H., Connolly, S. R., Chase, T. J., Dietzel, A., et al. (2019).

575 Global warming impairs stock-recruitment dynamics of corals. Nature. doi:10.1038/s41586$576 \quad 019-1081-y$.

577 Jeffrey, S. W., and Humphrey, G. F. (1975). New spectrophotometric equations for determining

578 chlorophylls a, b, c1 and c2 in higher plants, algae and natural phytoplankton. Biochem Physiol 579 Pflanz BPP. Available at: http://agris.fao.org/agris-

$580 \quad$ search/search.do?recordID=US201302771665.

581 Kenkel, C. D., Almanza, A. T., and Matz, M. V (2015a). Fine-scale environmental specialization of 582 reef-building corals might be limiting reef recovery in the Florida Keys. Ecology 96, 3197583 3212. doi:10.1890/14-2297.1.

584 Kenkel, C. D., Setta, S. P., and Matz, M. V (2015b). Heritable differences in fitness-related traits 585 among populations of the mustard hill coral, Porites astreoides. Heredity (Edinb). 115, 509. $586 \quad$ Available at: http://dx.doi.org/10.1038/hdy.2015.52. 
Knowlton, N. (1993). Sibling Species in the Sea. Annu. Rev. Ecol. Syst. 24, 189-216. doi:10.1146/annurev.es.24.110193.001201.

Korneliussen, T. S., Albrechtsen, A., and Nielsen, R. (2014). ANGSD: Analysis of Next Generation Sequencing Data. BMC Bioinformatics 15, 356. doi:10.1186/s12859-014-0356-4.

591 Ladner, J. T., and Palumbi, S. R. (2012). Extensive sympatry, cryptic diversity and introgression throughout the geographic distribution of two coral species complexes. Mol. Ecol. 21, 22242238. doi:doi:10.1111/j.1365-294X.2012.05528.x.

LaJeunesse, T. C., Parkinson, J. E., Gabrielson, P. W., Jeong, H. J., Reimer, J. D., Voolstra, C. R., et al. (2018). Systematic revision of Symbiodiniaceae highlights the antiquity and diversity of coral endosymbionts. Curr. Biol. doi:https://doi.org/10.1016/j.cub.2018.07.008.

Le Nohaïc, M., Ross, C. L., Cornwall, C. E., Comeau, S., Lowe, R., McCulloch, M. T., et al. (2017). Marine heatwave causes unprecedented regional mass bleaching of thermally resistant corals in northwestern Australia. Sci. Rep. 7, 1-11. doi:10.1038/s41598-017-14794-y.

Lefebure, T., Douady, C. J., Gouy, M., Trontelj, P., Briolay, J., and Gibert, J. (2006).

Phylogeography of a subterranean amphipod reveals cryptic diversity and dynamic evolution in extreme environments. Mol. Ecol. 15, 1797-1806.

Li, H., Handsaker, B., Wysoker, A., Fennell, T., Ruan, J., Homer, N., et al. (2009). The Sequence Alignment/Map format and SAMtools. Bioinformatics 25, 2078-2079. doi:10.1093/bioinformatics/btp352.

Louis, Y. D., Kaullysing, D., Gopeechund, A., Mattan-Moorgawa, S., Bahorun, T., Dyall, S. D., et al. (2016). In hospite Symbiodinium photophysiology and antioxidant responses in Acropora muricata on a coast-reef scale: implications for variable bleaching patterns. Symbiosis $68,61-$ 72. doi:10.1007/s13199-016-0380-4.

McClanahan, T., Maina, J., Moothien-Pillay, R., and Baker, A. (2005). Effects of geography, taxa, water flow, and temperature variation on coral bleaching intensity in Mauritius. Mar. Ecol. 
612 Prog. Ser. 298, 131-142. doi:10.3354/meps298131.

613 McClanahan, T. R., Baird, A. H., Marshall, P. A., and Toscano, M. A. (2004). Comparing bleaching 614 and mortality responses of hard corals between southern Kenya and the Great Barrier Reef, 615 Australia. Mar. Pollut. Bull. 48, 327-335. doi:10.1016/j.marpolbul.2003.08.024.

616 McClanahan, T. R., and Maina, J. (2003). Response of Coral Assemblages to the Interaction between 617 Natural Temperature Variation and Rare Warm-Water Events. Ecosystems 6, 551-563. 618 doi:10.1007/s10021-002-0104-x.

619 Moberg, F., and Folke, C. (1999). Ecological goods and services of coral reef ecosystems. Ecol. 620 Econ. 29, 215-233. doi:10.1016/S0921-8009(99)00009-9.

621 Morikawa, M. K., and Palumbi, S. R. (2019). Using naturally occurring climate resilient corals to 622 construct bleaching-resistant nurseries. Proc. Natl. Acad. Sci. 116, 10586-10591. 623 doi:10.1073/pnas.1721415116.

624 Oliver, T. A., and Palumbi, S. R. (2011). Do fluctuating temperature environments elevate coral 625 thermal tolerance? Coral Reefs 30, 429-440. doi:10.1007/s00338-011-0721-y.

626 Palumbi, S. R., Barshis, D. J., Traylor-Knowles, N., and Bay, R. A. (2014). Mechanisms of reef coral 627 resistance to future climate change. Science (80-. ). 344, 895-898. doi:10.1126/science.1251336. 628 Putnam, H. M., Stat, M., Pochon, X., and Gates, R. D. (2012). Endosymbiotic flexibility associates 629 with environmental sensitivity in scleractinian corals. Proc. R. Soc. B Biol. Sci. 279, $4352-4361$. $630 \quad$ doi:10.1098/rspb.2012.1454.

631 Richards, Z. T., Garcia, R. A., Wallace, C. C., Rosser, N. L., and Muir, P. R. (2015). A diverse 632 assemblage of reef corals thriving in a dynamic intertidal reef setting (Bonaparte Archipelago, 633 Kimberley, Australia). Public Libr. Sci. One 10, e0117791. doi:10.1371/journal.pone.0117791. 634 Richards, Z. T., Garcia, R., Moore, G., Fromont, J., Kirkendale, L., Bryce, M., et al. (2019). A 635 tropical Australian refuge for photosymbiotic benthic fauna. Coral Reefs. doi:10.1007/s00338$636 \quad 019-01809-5$. 
637 Riegl, B. M., Purkis, S. J., Al-Cibahy, A. S., Abdel-Moati, M. A., and Hoegh-Guldberg, O. (2011).

638 Present limits to heat-adaptability in corals and population-level responses to climate extremes.

639 Public Libr. Sci. One 6, e24802. doi:10.1371/journal.pone.0024802.

640 Rose, N. H., Bay, R. A., Morikawa, M. K., and Palumbi, S. R. (2017). Polygenic evolution drives

641 species divergence and climate adaptation in corals. Evolution (N. Y). 72, 82-94.

642 Safaie, A., Silbiger, N. J., McClanahan, T. R., Pawlak, G., Barshis, D. J., Hench, J. L., et al. (2018).

643 High frequency temperature variability reduces the risk of coral bleaching. Nat. Commun. 9, 644 1671. doi:10.1038/s41467-018-04074-2.

645 Schoepf, V., Carrion, S. A., Pfeifer, S. M., Naugle, M., Dugal, L., Bruyn, J., et al. (2019). Stress-

646 resistant corals may not acclimatize to ocean warming but maintain heat tolerance under cooler

647 temperatures. Nat. Commun. 10, 4031. doi:10.1038/s41467-019-12065-0.

648 Schoepf, V., Grottoli, A. G., Levas, S. J., Aschaffenburg, M. D., Baumann, J. H., Matsui, Y., et al.

649 (2015a). Annual coral bleaching and the long-term recovery capacity of coral. Proc. R. Soc. B

$650 \quad$ 282, 20151887. doi:10.1098/rspb.2015.1887.

651 Schoepf, V., Stat, M., Falter, J. L., and McCulloch, M. T. (2015b). Limits to the thermal tolerance of

652 corals adapted to a highly fluctuating, naturally extreme temperature environment. Sci. Rep. 5,

653 17639. doi:10.1038/srep17639.

654 Siebeck, U. E., Marshall, N. J., Klüter, A., and Hoegh-Guldberg, O. (2006). Monitoring coral

655 bleaching using a colour reference card. Coral Reefs 25, 453-460. doi:10.1007/s00338-006-

$656 \quad 0123-8$

657 Silverstein, R. N., Cunning, R., and Baker, A. C. (2015). Change in algal symbiont communities after 658 bleaching, not prior heat exposure, increases heat tolerance of reef corals. Glob Chang. Biol 21. 659 doi:10.1111/gcb.12706.

660 Skotte, L., Korneliussen, T. S., and Albrechtsen, A. (2013). Estimating individual admixture 661 proportions from Next Generation Sequencing data. Genetics. doi:10.1534/genetics.113.154138. 
662 Souter, P. (2010). Hidden genetic diversity in a key model species of coral. Mar. Biol. 157, 875-885.

663 doi:10.1007/s00227-009-1370-3.

664 Stat, M., and Gates, R. D. (2011). Clade D Symbiodinium in scleractinian corals: A "nugget” of

665 hope, a selfish opportunist, an ominous sign, or all of the above? J. Mar. Biol. 2011, 9.

$666 \quad$ doi:10.1155/2011/730715.

667 Szmant, A. M., and Gassman, N. J. (1990). The effects of prolonged "bleaching” on the tissue 668 biomass and reproduction of the reef coral Montastrea annularis. Coral Reefs 8, 217-224.

669 Therkildsen, N. O., and Palumbi, S. R. (2017). Practical low-coverage genomewide sequencing of 670 hundreds of individually barcoded samples for population and evolutionary genomics in nonmodel species. Mol. Ecol. Resour. 17, 194-208. doi:doi:10.1111/1755-0998.12593.

Thomas, L., Kendrick, G. A., Kennington, W. J., Richards, Z. T., and Stat, M. (2014). Exploring Symbiodinium diversity and host specificity in Acropora corals from geographical extremes of Western Australia with 454 amplicon pyrosequencing. Mol. Ecol. 23, 3113-3126. doi:10.1111/mec.12801.

Trygonis, V., and Sini, M. (2012). photoQuad: A dedicated seabed image processing software, and a comparative error analysis of four photoquadrat methods. J. Exp. Mar. Bio. Ecol. 424-425, 99-

van Woesik, R., Houk, P., Isechal, A. L., Idechong, J. W., Victor, S., and Golbuu, Y. (2012). Climate-change refugia in the sheltered bays of Palau: analogs of future reefs. Ecol. Evol. 2,

Vrijenhoek, R. C., Schutz, S. J., Gustafson, R. G., and Lutz, R. A. (1994). Cryptic species of deep-sea 683 clams (Mollusca: Bivalvia: Vesicomyidae) from hydrothermal vent and cold-water seep environments. Deep Sea Res. Part I Oceanogr. Res. Pap. 41, 1171-1189. doi:https://doi.org/10.1016/0967-0637(94)90039-6. 


\section{Supplementary Material}

1 Supplementary Figures and Tables

2 Supplementary Tables

3 Supplementary Table S1. Sample sizes for physiological analyses (area-normalized chlorophyll

$4 a$ concentration) for corals from (a) all genetic lineages and (b) the dominant lineage only. Coral

5 fragments were collected during and after the natural bleaching event in April and November 2016,

6 respectively.

7

\begin{tabular}{|c|c|c|c|c|}
\hline & \multicolumn{2}{|c|}{ Intertidal } & \multicolumn{2}{|r|}{ Subtidal } \\
\hline & healthy & bleached/recovered & healthy & bleached/recovered \\
\hline \multicolumn{5}{|c|}{ (a) All genetic lineages } \\
\hline April 2016 & 10 & 6 & 10 & 5 \\
\hline Nov. 2016 & 9 & 5 & 3 & 1 \\
\hline \multicolumn{5}{|c|}{ (b) dominant genetic lineage only } \\
\hline April 2016 & 7 & 3 & 10 & 2 \\
\hline Nov. 2016 & 6 & 2 & 3 & 0 \\
\hline
\end{tabular}

8

9

10 
11 Supplementary Table S2. Generalized linear mixed model (GLMM) analyses testing the effect

12 of genetic lineage on chlorophyll $\boldsymbol{a}$ concentration measured on intertidal and subtidal Acropora

13 aspera corals collected in April and November 2016. Num df = numerator degrees of freedom, den

$14 \mathrm{df}=$ denominator degrees of freedom.

15

\begin{tabular}{cccccc}
\hline Analysis & Factor levels & Num df & Den df & $\boldsymbol{F}$-statistic & $\boldsymbol{p}$-value \\
\hline All lineages included & $1,2,3$ & 2 & 46 & 0.29 & 0.7462 \\
\hline Two dominant lineages only & 1,2 & 1 & 42 & 0.39 & 0.5338 \\
\hline
\end{tabular}

16

17

18 
19 Supplementary Table S3. Generalized linear mixed model (GLMM) analyses testing the effect

20 of environment, health and time on chlorophyll $a$ concentration of Acropora aspera from all

21 genetic lineages and the dominant lineage only. Post hoc Tukey tests results are given when main 22 effects (but no interaction terms) were significant. Effects with $p$-values $\leq 0.05$ are highlighted in 23 bold. Num $\mathrm{df}=$ numerator degrees of freedom, den $\mathrm{df}=$ denominator degrees of freedom. Note that 24 the three-way interaction could not be assessed for the dominant lineage corals because none of the 25 tagged bleached subtidal corals from lineage 1 survived.

\begin{tabular}{clccccc}
\hline Var. & \multicolumn{1}{c}{ Effect } & Num df & Den df & $\boldsymbol{F}$-statistic & $\boldsymbol{p}$-value & Tukey \\
\hline all & Env. & 1 & 41 & 0.77 & 0.3845 & \\
lineages & Health & 1 & 41 & 27.31 & $<\mathbf{0 . 0 0 0 1}$ & \\
& Env. ${ }^{*}$ health & 1 & 41 & 12.94 & $\mathbf{0 . 0 0 0 9}$ & \\
& Time & 1 & 41 & 131.15 & $<\mathbf{0 . 0 0 0 1}$ & \\
& Env. $*$ time & 1 & 41 & 2.73 & 0.1064 & \\
& Health * time & 1 & 41 & 30.67 & $<\mathbf{0 . 0 0 0 1}$ & \\
& Env. * health * time & 1 & 41 & 8.70 & $\mathbf{0 . 0 0 5 2}$ & See text \\
\hline dominant & Env. & 1 & 26 & 1.61 & 0.2160 & \\
lineage & Health & 1 & 26 & 42.99 & $<\mathbf{0 . 0 0 0 1}$ & \\
& Env. $*$ health & 1 & 26 & 16.80 & $\mathbf{0 . 0 0 0 4}$ & See text \\
& Time & 1 & 26 & 71.53 & $<\mathbf{0 . 0 0 0 1}$ & \\
& Env. * time & 1 & 26 & 1.02 & 0.3216 & \\
& Health * time & 1 & 26 & 13.52 & $\mathbf{0 . 0 0 1 1}$ & See text \\
& Env. $*$ health $*$ time & 0 &. &. & & \\
\hline
\end{tabular}


(a)

10-12 April 2016

2500

in 2000

है 1500

을

死 1000

高 500

0

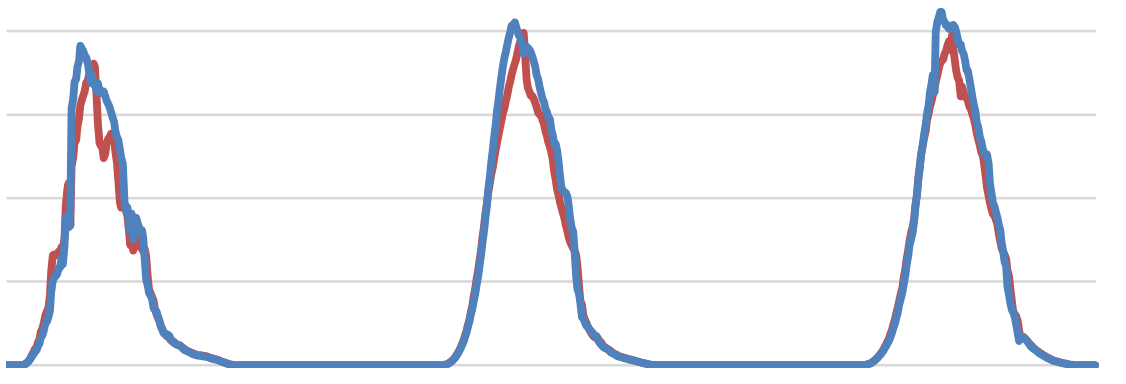

Intertidal

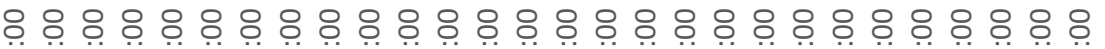

ठ்

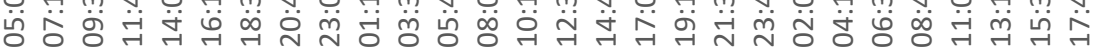

Time of day

(b)

17-20 October 2016

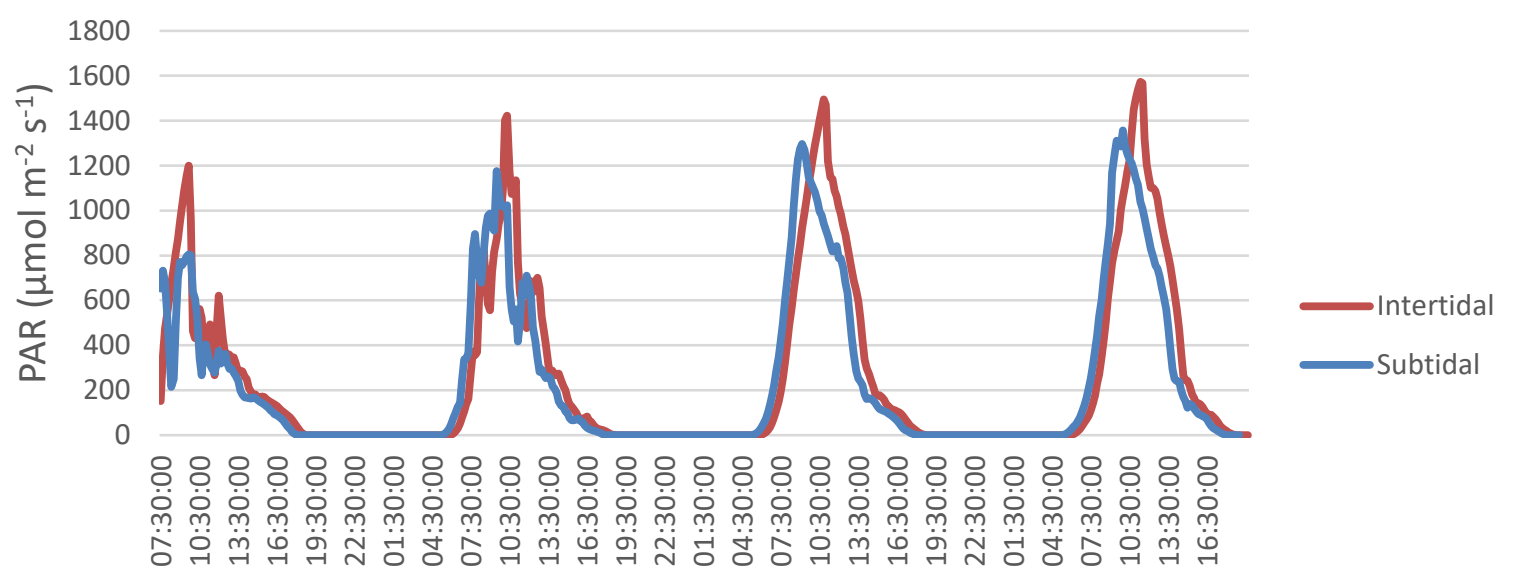

Time of day

34 Supplementary Figure S1. Photosynthetically active radiation (PAR) measured in the intertidal and 35 subtidal over a spring tide in (a) April and (b) October 2016. 


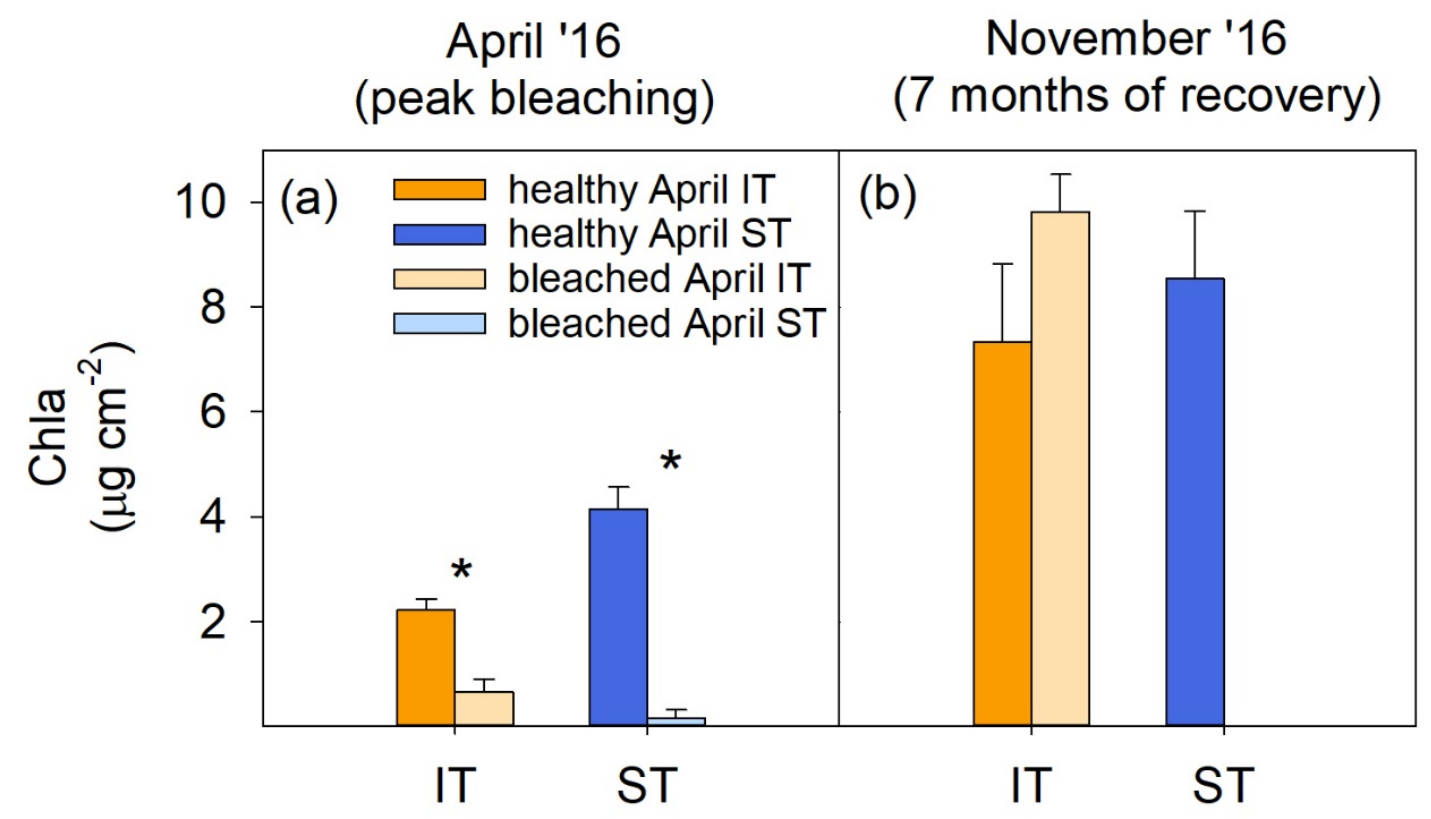

38 Supplementary Figure S2. Coral physiology for the dominant genetic lineage. Area-normalized

39 chlorophyll $a$ concentration of intertidal (IT) and subtidal (ST) Acropora aspera (lineage 1 only) in

40 (a) April and (b) November 2016. Asterisks indicate significant differences between healthy and

41 bleached/recovering corals within a specific environment and time point. Note that none of the

42 tagged bleached subtidal corals from lineage 1 survived. 